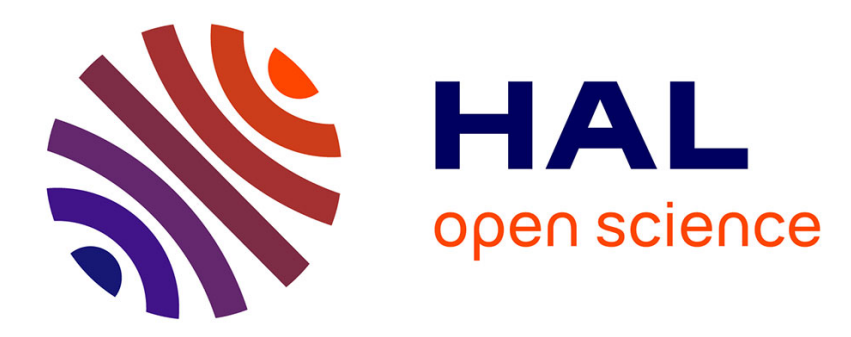

\title{
Organized growth of carbon nanotubes on Fe-doped alumina ceramic substrates
}

Ender Suvaci, Yasemin Çelik, Alicia Weibel, Alain Peigney, Emmanuel

Flahaut

\section{- To cite this version:}

Ender Suvaci, Yasemin Çelik, Alicia Weibel, Alain Peigney, Emmanuel Flahaut. Organized growth of carbon nanotubes on Fe-doped alumina ceramic substrates. Carbon, 2012, vol. 50, pp. 3092-3095. 10.1016/j.carbon.2012.02.034 . hal-00857439

\section{HAL Id: hal-00857439 \\ https://hal.science/hal-00857439}

Submitted on 3 Sep 2013

HAL is a multi-disciplinary open access archive for the deposit and dissemination of scientific research documents, whether they are published or not. The documents may come from teaching and research institutions in France or abroad, or from public or private research centers.
L'archive ouverte pluridisciplinaire HAL, est destinée au dépôt et à la diffusion de documents scientifiques de niveau recherche, publiés ou non, émanant des établissements d'enseignement et de recherche français ou étrangers, des laboratoires publics ou privés. 


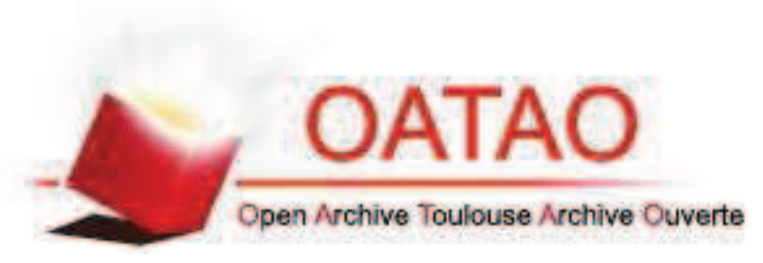

\section{Open Archive Toulouse Archive Ouverte (OATAO)}

OATAO is an open access repository that collects the work of Toulouse researchers and makes it freely available over the web where possible.

This is an author-deposited version published in: http://oatao.univ-toulouse.fr/ Eprints ID: 8724

To link to this article: DOI: $10.1016 /$ j.carbon.2012.02.034

URL: http://dx.doi.org/10.1016/j.carbon.2012.02.034

To cite this version: Suvacı, Ender and Çelik, Yasemin and Weibel, Alicia and Peigney, Alain and Flahaut, Emmanuel Organized growth of carbon nanotubes on Fe-doped alumina ceramic substrates. (2012) Carbon, vol. $50\left(\mathrm{n}^{\circ} 8\right)$. pp. 3092-3095. ISSN 0008-6223 


\title{
Organized growth of carbon nanotubes on Fe-doped alumina ceramic substrates
}

\author{
Ender Suvacl ${ }^{a, *}$, Yasemin Çelik ${ }^{a}$, Alicia Weibel ${ }^{b}$, Alain Peigney ${ }^{b}$, Emmanuel Flahaut ${ }^{b, c}$ \\ a Anadolu University, Department of Materials Science and Engineering, 26480 Eskişehir, Turkey \\ ${ }^{\mathrm{b}}$ Université de Toulouse, UPS, INP, Institut Carnot Cirimat, 118, route de Narbonne, F-31062 Toulouse cedex 9, France \\ c CNRS, Institut Carnot Cirimat, F-31062 Toulouse, France
}

\begin{abstract}
A B S T R A C T
Polycrystalline Fe-doped alumina $\left(\mathrm{Al}_{2} \mathrm{O}_{3}\right)$ ceramics have been produced and used as a substrate for organized carbon nanotubes (CNTs) growth by catalytic chemical vapor deposition (CCVD). In these substrates, $\mathrm{Fe}^{3+}$ cations, which are the catalyst source, are initially substituted to $\mathrm{Al}^{3+}$ in $\alpha-\mathrm{Al}_{2} \mathrm{O}_{3}$, instead of being simply deposited as a thin Fe layer on the surface of the substrate. The selective reduction of these substrates resulted in in situ formation of homogeneously distributed Fe nanoparticles forming patterns at nanometerscale steps and kinks. These nanoparticles then catalyzed the growth of high quality CNTs, with some degree of organization thanks to their interaction with the topography of the substrate.
\end{abstract}

Carbon nanotubes (CNTs) are good candidates for future nanoelectronic devices owing to their unique properties [1]. However, the technological obstacle to expand their utilization in electronics is the difficulty in growing CNTs directly on a substrate by controlling their location and orientation. One of the key issues to overcome this obstacle is precise placement and size control of metal nanoparticles, which act as catalysts for CNTs growth by CCVD, over the substrate. Various lithographical methods have been investigated to pattern catalysts [2]. However, the use of costly equipments urges to develop simpler and more accessible techniques for uniform and individual generation of catalytic nanoparticles. CCVD growth of CNTs on ceramics, where the catalyst source was mostly deposited as a continuous thin film on the substrate surface, has been studied by several authors [3,4]. Randomly oriented or aligned CNTs were produced over these surfaces depending on the metallic film thickness, as well as the substrate properties, such as surface morphology and degree of crystallinity. This letter reports a new substrate for CNTs growth, polycrystalline Fe-doped $\mathrm{Al}_{2} \mathrm{O}_{3}$ ceramic, where the catalyst source ( $\mathrm{Fe}^{3+}$ cations) is initially located as substitution to $\mathrm{Al}^{3+}$ in $\alpha-\mathrm{Al}_{2} \mathrm{O}_{3}$, instead of a continuous thin Fe film deposited on the surface. When the sintered Fe-doped $\mathrm{Al}_{2} \mathrm{O}_{3}$ substrate is subjected to CCVD, substitutional Fe $\mathrm{Fe}^{3+}$ cations are first selectively reduced to metallic Fe atoms, which then nucleate into clusters and end up as nanoparticles [5]. Since $\mathrm{Fe}^{3+}$ cations are located at certain sites in $\mathrm{Al}_{2} \mathrm{O}_{3}$ lattice, homogeneously distributed $\mathrm{Fe}$ nanoparticles are in situ achieved throughout the substrate surface, and preferentially located at the steps and kinks. These surface nanoparticles then react with a carbon source $\left(\mathrm{CH}_{4}\right)$, and catalyze $\mathrm{CNT}$ growth.

The Fe-doped $\mathrm{Al}_{2} \mathrm{O}_{3}$ ceramic substrates were produced from Fe-doped $\mathrm{Al}_{2} \mathrm{O}_{3}$ powders which were synthesized in the form of solid solutions by combustion synthesis route [6]. These powders were shaped to form Fe-doped $\mathrm{Al}_{2} \mathrm{O}_{3}$ ceramic

\footnotetext{
* Corresponding author: Fax: +90 2223239501.

E-mail address: esuvaci@anadolu.edu.tr (E. Suvacı).
} 
substrates by tape casting. The tape casting slurry consisted of $\alpha-\mathrm{Al}_{1.8} \mathrm{Fe}_{0.2} \mathrm{O}_{3}$ powder with a specific surface area of $33 \mathrm{~m}^{2} / \mathrm{g}$, an azeotropic mixture of methylethylketon ( $66 \mathrm{vol} . \%)$ and ethanol (34 vol.\%) as solvent, sodiumtripolyphosphate (STPP) as dispersant, polyvinylbutyral (PVB Butvar 76) as binder, and polyethylene glycol (PEG 3000, Fluka, Steinheim, Switzerland) and dibutylphthalate (DBP) as plasticizers. The slurry was prepared by mixing the constituents in a ball mill for $21 \mathrm{~h}$ in total. The prepared slurry was tape casted on a glass plate at a blade height of $400 \mu \mathrm{m}$ at a $30 \mathrm{~cm} / \mathrm{s}$ casting speed. After drying at ambient conditions for $30 \mathrm{~min}$, the tape was cut and laminated at $45 \mathrm{MPa}$ and $70^{\circ} \mathrm{C}$ for $10 \mathrm{~min}$. After removal of organics at $450{ }^{\circ} \mathrm{C}$ for $2 \mathrm{~h}$, the samples were sintered at $1400-1600{ }^{\circ} \mathrm{C}$ for $2 \mathrm{~h}$ in air. The samples were then placed in alumina boats in the middle of a CCVD chamber and reduced in $\mathrm{H}_{2}-\mathrm{CH}_{4}$ gas mixture $\left(82 \mathrm{~mol} \% \mathrm{H}_{2}\right.$ as reducing gas and $18 \mathrm{~mol} \% \mathrm{CH}_{4}$ as carbon source) at $1000{ }^{\circ} \mathrm{C}$ with a heating and cooling rate of $5 \%$ min. No dwell time was applied [5]. After CCVD, the substrates were characterized by field emission gun scanning electron microscope (FEG-SEM, Jeol JSM 6700F) and Raman spectrometry (Dilor XY micro-Raman set-up with back-scattering geometry, $\lambda=632.82 \mathrm{~nm}$ ). Moreover, to examine the distribution of catalysts over the surface, the substrates were reduced in only $\mathrm{H}_{2}$ atmosphere at $1000^{\circ} \mathrm{C}$ (as a control experiment, following the same heating cycle as described above) and then observed by FEG-SEM.

Fig. 1 shows the scanning electron microscopy (SEM) images of the Fe-doped $\mathrm{Al}_{2} \mathrm{O}_{3}$ substrates, which were exposed to $100 \% \mathrm{H}_{2}$ atmosphere at $1000{ }^{\circ} \mathrm{C}$. These images revealed in situ catalyst decoration over polycrystalline Fe-doped $\mathrm{Al}_{2} \mathrm{O}_{3}$ ceramics. The individual Fe nanoparticles are homogeneously distributed throughout the surface (Fig. 1a) and preferentially located at nanometer-scale kinks (Fig. 1a) and steps (Fig. 1b), which were formed during sintering of the ceramic. These areas (steps and kinks) are energetically favorable for Fe nanoparticles.

The Fe-doped $\mathrm{Al}_{2} \mathrm{O}_{3}$ ceramic substrates, which were exposed to CCVD in $\mathrm{H}_{2}-\mathrm{CH}_{4}$ gas mixture [5] have been imaged by FEG-SEM using a low acceleration voltage $(1 \mathrm{kV})$ and an in-lens electron detector, revealing the growth details of CNTs over these substrates (Fig. 2). Fig. 2a shows a huge contrast between the insulating substrate and the CNTs, which highlights the topography of the substrate such as steps (on this SEM image, CNTs appear in white, while the insulating sub- strate appears in black). This type of contrast was also observed by Brintlinger et al. [7] and Homma et al. [8], who demonstrated separately the imaging of nanotubes on insulating substrates by scanning electron microscopy operated at low acceleration voltage. Fig. 2a clearly shows CNTs organized along the steps of the ceramic substrate. It should be noted that this contrast was not observed in all regions of the substrates in the present study. This may arise from different orientation of each grain on the substrate surface, since it affects electron beam-sample interaction.

Fig. $2 \mathrm{~b}$ shows the randomly oriented CNTs over Fe-doped $\mathrm{Al}_{2} \mathrm{O}_{3}$ substrate. The CNTs which are in contact with the substrate appear darker and those which are not in contact appear brighter than the substrate. The CNTs yield is relatively low with respect to the total number of catalytic nanoparticles. This indicates that some of them were not active during CNT growth. The variation in catalytic nanoparticle size may arise from the variation of cluster formation kinetics depending on the substrate surface morphology and crystallographic orientation of the grains. Terrado et al. [3] reported randomly oriented MWCNT CCVD synthesis on catalyst film deposited $\mathrm{Al}_{2} \mathrm{O}_{3}$, while they achieved vertically aligned MWCNTs on quartz substrates on the same experimental conditions, suggesting that the substrate morphology and surface chemistry may play an important role in the final CNT orientation. The authors also suggested that high densities of catalytic nanoparticles (and consequently high amount of CNTs) were required in order to achieve well vertically aligned CNTs. They proposed that at high temperatures, the catalysts which are tens of nanometers in size may rapidly diffuse and coalesce on the substrate forming bigger catalyst nanoparticles [3]. When nanoparticles are formed in situ at high temperature in $\mathrm{H}_{2}-\mathrm{CH}_{4}$ atmosphere as in the present work, they become rapidly covered by carbon which limits or inhibits their coalescence and keep them at the appropriate size for growing CNTs. Ward et al. [4] investigated the effects of various substrates on the growth of CNTs and suggested that the degree of substrate crystallinity and surface roughness had a strong influence on nanotube formation. They grew randomly oriented SWCNTs over thin Mo-Fe-Al film coated amorphous $\mathrm{Al}_{2} \mathrm{O}_{3}$, which provided high dispersion of Fe catalysts on the substrate surface. However, they could not explain what property of the substrate allowed for this high dispersion [4]. It is interesting to compare the metal nanoparticles on
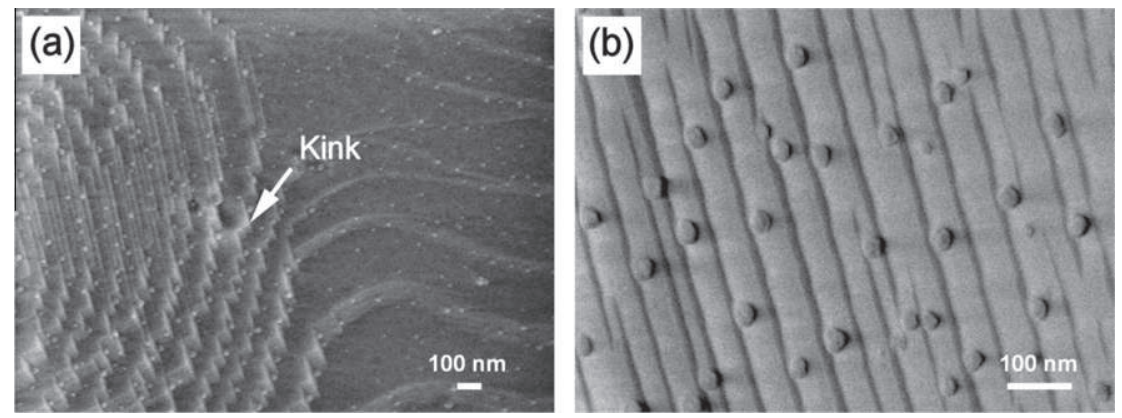

Fig. 1 - FEG-SEM images of the Fe-doped $\mathrm{Al}_{2} \mathrm{O}_{3}$ ceramic substrates after reduction in $\mathrm{H}_{2}$ atmosphere at $1000{ }^{\circ} \mathrm{C}$. (a) SEM image showing evenly distributed Fe nanoparticles throughout the surface and in the kinks. (b) High magnification SEM image showing in situ formed catalyst patterns along the steps. The size of most particles is around $25-30 \mathrm{~nm}$. 

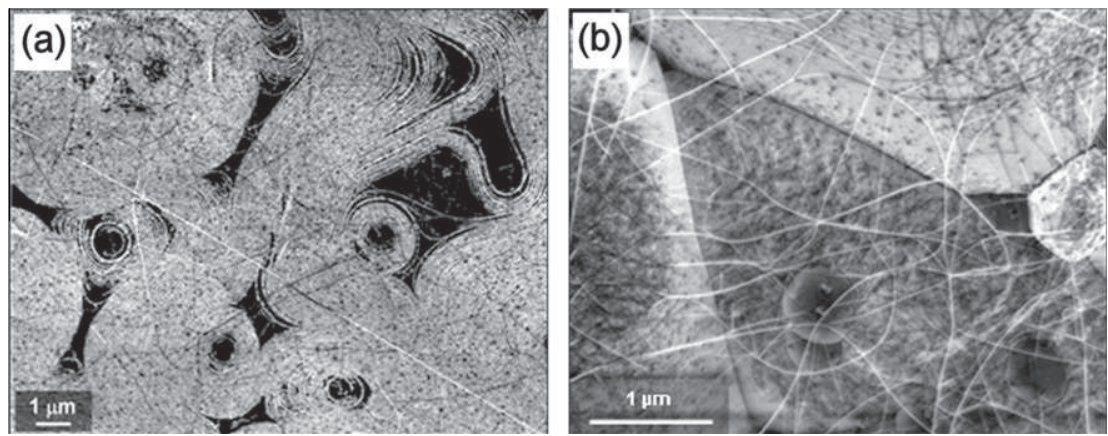

Fig. 2 - CNTs formation over Fe-doped $\mathrm{Al}_{2} \mathrm{O}_{3}$ ceramics. (a) FEG-SEM image illustrating the contrast between the insulating substrate and the CNTs (CNTs in white) and their organization along the steps. (b) FEG-SEM image of randomly oriented CNTs bridging the grains in other areas.

Fig. 1 (obtained after simple reduction in $\mathrm{H}_{2}$ ) and on Fig. 3 (after air oxidation at $900^{\circ} \mathrm{C}$ for $2 \mathrm{~h}$ of the substrates after CCVD growth of CNTs). Comparing Figs. 1 and 3, the high contrast which was visible in Fig. $2 \mathrm{a}$ is not observed any more on Fig. 3, which confirms that it was indeed due to the presence of CNTs (deliberately, completely burned on Fig. 3 after the high-temperature oxidation treatment) and not to the presence of the steps themselves. In the first case, the diameter distribution of nanoparticles is rather monomodal (25-30 nm). In the second case, we can clearly see two populations of nanoparticles, one being very similar to the particles on Fig. 1, and the other one being much smaller.

It is assumed that the smaller particles correspond to the ones which catalyzed the growth of CNTs, because any coalescence was then prevented as soon as the growth of a CNT was initiated. As these nanoparticles are generated in situ and the carbon source is available, the CNT growth can be initiated as soon as the right conditions are gathered (matching size between the diameter of the nanoparticle and the CNT to be grown on it, adequate carbon concentration). The distribution of these suitable nanoparticles is expected to be homogeneous (random) at the surface of the alumina substrate, as the nanoparticles are generated by selective reduction of a solid solution. The other population of larger nanoparticles corresponds to catalytically inactive nanoparticles. This phenomenon was already observed in the case of $\mathrm{CNT}-\mathrm{Fe}-\mathrm{Al}_{2} \mathrm{O}_{3}$ powders obtained by a similar CCVD process [9].
Fig. 4 shows the Raman spectra of polycrystalline Fe-doped $\mathrm{Al}_{2} \mathrm{O}_{3}$ ceramic substrate before and after the CCVD process. Before the CCVD, the spectrum of the substrate shows only the peaks belonging to the ceramic substrate. When the substrate was subjected to the CCVD, so-called D-band (disorder peak, $\sim 1320 \mathrm{~cm}^{-1}$ ) and G-band (tangential vibrations of $\mathrm{sp}^{2}$ carbon atoms, $\sim 1575 \mathrm{~cm}^{-1}$ ) were detected in the Raman spectrum (Fig. $4 \mathrm{a})$. The D-band to G-band intensity ratio $\left(\mathrm{I}_{\mathrm{D} / \mathrm{G}}\right)$ is $18 \%$ for this sample. An increasing $I_{D / G}$ value is generally attributed to the presence of more structural defects. Therefore, the low $I_{D / G}$ ratio, achieved in this study, can be attributed to high quality CNTs with low amount of undesired carbon phases (carbon nanofibres or carbon nanorods and/or disorganized carbon). The radial breathing mode (RBM) peaks, observed in the low frequency region $(115,120,132.7,168.7$ and $177.7 \mathrm{~cm}^{-1}$ ) of the spectrum (Fig. 4b), indicate that at least part of the CNTs have only a few walls. Moreover, the splitting of the G-band (Fig. 4a) can be attributed to the presence of single-walled CNTs. The diameter distribution calculated from the frequency of the RBM peaks [10] is ranging between 1.26 and $1.95 \mathrm{~nm}$. It must however be reminded that the population of CNTs which can be investigated by Raman spectroscopy strongly depends on the wavelength of the laser used, so even if limitations occur for large diameters (and not for small ones), the diameter distribution obtained by this technique can only be used as an additional information.

In conclusion, polycrystalline Fe-doped $\mathrm{Al}_{2} \mathrm{O}_{3}$ ceramics have been shown as new potential ceramic substrates for
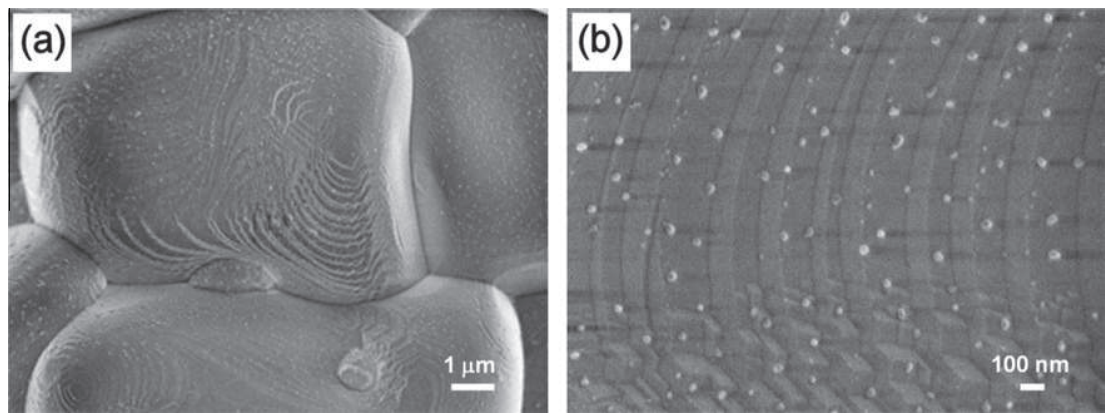

Fig. 3 - FEG-SEM images of the Fe-doped $\mathrm{Al}_{2} \mathrm{O}_{3}$ ceramic substrates after CCVD followed by air oxidation at $900{ }^{\circ} \mathrm{C}(2 \mathrm{~h})$ in order to remove all carbon material. (a) Image showing evenly distributed Fe oxide nanoparticles throughout the surface. (b) High magnification image showing the diameter distribution of the oxide nanoparticles as well as their localization. 

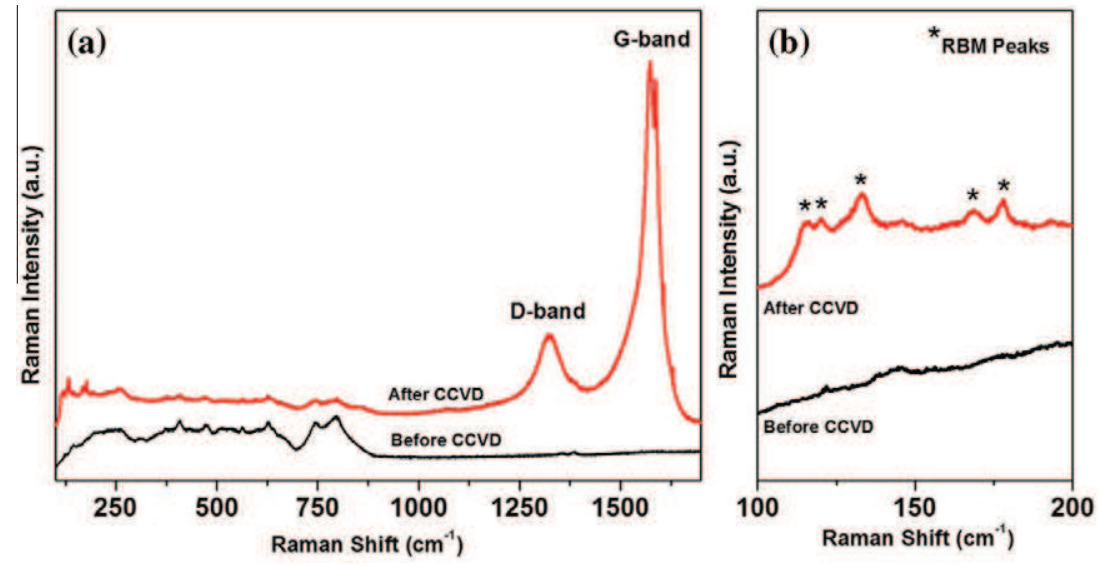

Fig. 4 - (a) Raman spectra of Fe-doped $\mathrm{Al}_{2} \mathrm{O}_{3}$ ceramic substrate before and after CCVD. (b) Low frequency region of the spectra focusing on the RBM peaks.

organized CNTs synthesis by CCVD. The in situ reduction of substitutional $\mathrm{Fe}^{3+}$ cations leads to Fe nanoparticles preferentially localized along the steps and kinks of the ceramic surface which allows the growth of high quality organized CNTs. This work opens new routes for uniform and individual distribution of catalysts for synthesis of CNTs with a controlled orientation at desired locations in a patterned form.

\section{Acknowledgements}

The financial support for this study by The Scientific and Technological Research Council of Turkey (TUBITAK) and Centre National de la Recherche Scientifique (CNRS) under the contract number 106M543 is gratefully acknowledged. One of the authors, E. Suvaci, thanks to Turkish Academy of Sciences (TUBA) for financial support through Outstanding Young Investigator Award (GEBIP) Program. The authors also thank to Lucien Datas for assistance in the FESEM observations (which were performed at "service commun TEMSCAN", Université Paul-Sabatier) and to Markus König of TU Darmstadt for his contribution during preliminary studies.

\section{R E F E R E N C E S}

[1] Saito R, Dresselhaus G, Dresselhaus MS. Physical properties of carbon nanotubes. London: Imperial College Press; 1998.
[2] Yang Y, Huang S, He H, Mau AW, Dai L. Patterned growth of well-aligned carbon nanotubes: a photolithographic approach. J Am Chem Soc 1999;121:10832-3.

[3] Terrado E, Redrado M, Munoz E, Maser WK, Benito AM, Martinez MT. Aligned carbon nanotubes grown on alumina and quartz substrates by a simple thermal CVD process. Diamond Relat Mater 2006;15:1059-63.

[4] Ward JW, Wei BQ, Ajayan PM. Carbon nanotubes by thermal decomposition of methane. Chem Phys Lett 2003;376:717-25.

[5] Peigney A, Laurent Ch, Dobigeon F, Rousset A. Carbon nanotubes grown in situ by a novel catalytic method. J Mater Res 1997;12(3):613-5.

[6] Cordier A, Peigney A, De Grave E, Flahaut E, Laurent C. Synthesis of the metastable $\alpha-\mathrm{Al}_{1.8} \mathrm{Fe}_{0.2} \mathrm{O}_{3}$ solid solution from precursors prepared by combustion. J Eur Ceram Soc 2006;26:3099-111.

[7] Brintlinger T, Chen YF, Dürkop T, Cobas E, Fuhrer MS, Barry JD, et al. Rapid imaging of nanotubes on insulating substrates. Appl Phys Lett 2002;81:2454-6.

[8] Homma Y, Suzuki S, Kobayashi Y, Nagase M, Takagi D. Mechanism of bright selective imaging of single-walled carbon nanotubes on insulators by scanning electron microscopy. Appl Phys Lett 2004;84:1750-2.

[9] Peigney A, Coquay P, Flahaut E, Vandenberghe RE, De Grave E, Laurent C. A study of the formation of single- and doublewalled carbon nanotubes by a CVD method. J Phys Chem B 2001;105:9699-710.

[10] Bandow S, Asaka S, Saito Y, Rao AM, Grigorian L, Richter E, et al. Effect of the growth temperature on the diameter distribution and chirality of single-wall carbon nanotubes. Phys Rev Lett 1998;80:3779-82. 